\title{
Pemanfaatan Alat Standar Primer untuk Peningkatan Kualitas Nilai Kalibrasi Alat Ukur Radioaktivitas di Bidang Kedokteran Nuklir
}

\section{Gatot Wurdiyanto dan Pujadi}

Pusat Teknologi Keselamatan dan Metrologi Radiasi (PTKMR) - Badan Tenaga Nuklir Nasional (BATAN)

Jalan Lebak Bulus Raya, No. 49. Jakarta Selatan, 12740

Gatot_w@batan.go.id

\begin{abstract}
Abstrak - Pemanfaatan teknologi nuklir di bidang kesehatan yang menggunakan teknologi Positron Emission Tomography (PET) telah berkembang dengan pesat di Indonesia. Teknologi PET tersebut memanfaatkan sumber radioaktif ${ }^{18} \mathrm{~F}$ sebagai perunut yang digunakan untuk mendiagnosis berbagai penyakit. Laboratorium Metrologi Radiasi pada PTKMR - BATAN, yang mempunyai tugas dan fungsi sebagai laboratorium acuan nasional di bidang radiasi pengion berperan dalam melakukan tugas untuk melakukan standardisasi radionuklida dan mengkalibrasi alat ukur aktivitas. Pada mulanya, kalibrasi alat ukur aktivitas "dose calibrator" di rumah sakit menggunakan alat standar sekunder yang tertelusur ke laboratorium primer LMRI (Laboratoire Metrologie Ranyonnements Ionisants), melalui standardisasi ${ }^{18} \mathrm{~F}$ dilakukan menggunakan metode spektrometri$\gamma$. Dengan cara seperti ini didapatkan hasil kalibrasi dengan nilai ketidakpastian bentangan 6,3\%. Untuk meningkatkan kualitas hasil pengukuran, dilakukan standardisasi ${ }^{18} \mathrm{~F}$ menggunakan alat standar primer dengan metode absolut koinsidensi $4 \pi \beta(L S)-\gamma$. Dengan metode ini didapatkan nilai ketidakpastian bentangan 2,9\% dengan faktor cakupan, $k=2$, dan tingkat kepercayaan 95\%. Dengan berhasilnya penelitian ini diharapkan Laboratorium Standardisasi Radionuklida PTKMRBATAN dapat berperan dalam kalibrasi alat ukur aktivitas secara kontinu agar pemanfaatan teknologi nuklir di bidang kesehatan dapat terlaksana dengan aman dan selamat baik bagi pekerja, masyarakat maupun lingkungannya.
\end{abstract}

Kata kunci : Kalibrasi, standardisasi radionuklida, ${ }^{18} \mathrm{~F}$, spektrometri $\gamma, \quad$ koinsidensi $4 \pi \beta(L S)-\gamma$.

Abstract - Utilization Primary Standards Apparatus for Quality Improvement of Calibration Value of Radioactivity Instrument in the Nuclear Medicine Field. The use of nuclear technology in the health sector utilizing Positron Emission Tomography (PET) technology has grown rapidly in Indonesia. PET technology utilizes a radioactive source that is used as a tracer ${ }^{18} \mathrm{~F}$ to diagnose various diseases. The Radionuclide Standardization Laboratory at the Center for Technology of Radiation Safety and Metrology - National Nuclear Energy Agency, which has the duty and function as a national reference laboratories in the field of radionuclide activity measurement, plays a role in calibrating the activity measurement instruments. At first, calibration of measuring instruments of activity" dose calibrator " in the hospital using a secondary standard traceable to primary LMRI laboratory ( Laboratoire Metrologie Ranyonnements Ionisants ), through standardization was performed using ${ }^{18} F$ - spectrometry method $\gamma$. By this methods have been obtained results of calibration factor is 1.00 with a $6.3 \%$ of expanded uncertainty values. To improve the precision and accuracy of measurement, standardization of ${ }^{18} F$ is done using an absolute measurement instruments $4 \pi \beta(L S)-\gamma$ coincidence system. With this method the uncertainty stretch the value obtained with the $2.9 \%$ coverage factor, $k=2$, and the level of confidence $95 \%$. With the success of this research is expected Radionuclide Standardization Laboratory PTKMR - BATAN can play a role in the calibration of measuring instruments of activities continuously that use of nuclear technology in the health sector can be accomplished safely and survived well for workers, communities and the environment.

Key words: Calibration, $\quad$ radionuclide standardization, ${ }^{18} \mathrm{~F}, \gamma$ spectrometry, $4 \pi \beta(L S)$ - $\gamma$ coincidence.

\section{PENDAHULUAN}

Perkembangan pemanfaatan teknologi nuklir dalam bidang kesehatan telah memasuki era baru di Indonesia. Hal ini ditandai dengan masuknya teknologi Positron Emission Tomography/Computed Tomography (PET/CT) ke Indonesia yang menunjukkan semakin berkembangnya pemanfaatan teknologi nuklir di bidang kesehatan. PET/CT merupakan teknik pencitraan nuklir secara noninvasive yang meliputi pemberian radiofarmaka yang memancarkan positron dan pencitraan serta distribusi dan gerakan material radioaktif perunut.
Seiring dengan pemanfaatan pesawat PET/CT, diperlukan suatu perangkat lain yang mendukung kegitan tersebut sebagai kontrol kualitas. Seperti diketahui, aplikasi pesawat PET/CT diikuti dengan keberadaan mesin pemercepat elektron (cyclotron) yang akan memproduksi sumber radionuklida berumur paro sangat pendek seperti ${ }^{18} \mathrm{~F}$ sebagai material perunut. Ukuran atau aktivitas dari sumber radionuklida ${ }^{18} \mathrm{~F}$ perlu diukur secara teliti dan akurat sebelum disuntikkan ke pasien. Alat ukur yang digunakan untuk mengukur aktivitas adalah dose calibrator, atau dikenal juga dengan radionuclide calibrator. Alat ini adalah alat utama sebagai kontrol kualitas besaran dari 
sumber radioaktif yang akan disuntikkan ke pasien. Alat in dipilih karena penggunaannya sangat praktis, sederhana, mudah, cepat dan sangat stabil dibanding alat ukur aktivitas lainnya. Meskipun demikian, alat ini membutuhkan kontrol yang ketat dengan cara mengkalibrasi secara berkala ke laboratorium acuan menggunakan sumber standar yang sesuai. Kesalahan dalam pengukuran aktivitas menyebabkan diagnosis/terapi menjadi tidak tepat. Efek samping terhadap pasien bila mendapat dosis aktivitas yang berlebihan kemungkinan akan mengakibatkan kanker pada organ yang terkena paparan radiasi.

Berdasar pada tugas dan fungsinya sebagai laboratorium acuan nasional dalam bidang pengukuran radioaktivitas, maka peran PTKMR dalam kegiatan PET/CT adalah melakukan kalibrasi alat ukur radiasi/aktivitas. Pada penelitian sebelumnya, Gatot W., dkk [1] telah melakukan kalibrasi dose kalibrator dimana sumber standar ${ }^{18} \mathrm{~F}$ yang digunakan distandarkan menggunakan metode spektrometri gamma. Untuk meningkatkan kualitas hasil pengukuran, pada penelitian ini standardisasi ${ }^{18} \mathrm{~F}$ dilakukan dengan metode absolut menggunakan perangkat absolut koinsidensi $4 \pi \beta(\mathrm{LS})-\gamma$. Perangkat ini merupakan alat standar primer yang digunakan di laboratorium primer di negara maju.

Metode absolut dipilih karena pengukuran dilakukan tanpa menggunakan sumber standar, sehingga hasil pengukuran memiliki nilai akurasi dan ketepatan yang sangat tinggi dengan nilai ketidakpastian di bawah $1 \%$. Tingkat kemurnian dari radionuklida ${ }^{18} \mathrm{~F}$ dianalisis dengan menggunakan perangkat spektrometer gamma.

${ }^{18} \mathrm{~F}$ merupakan radionuklida yang mempunyai umur paro sangat pendek, yaitu 109,77 menit, meluruh dengan model tangkapan elektron dan memancarkan gamma pada energi $511 \mathrm{KeV}$ menjadi ${ }^{18} \mathrm{O}[2-3]$. Dengan sifat seperti ini, dalam melakukan standardisasi perlu memperhatikan beberapa faktor yang mempengaruhi pengukuran radioaktivitasnya. Karena umur paro sangat pendek maka akan ada peluruhan aktivitas selama pengukuran. Untuk itu perlu dipertimbang-kan lama pengukuran dengan pengaruh peluruhan aktivitas-nya. Selanjutnya sumber standar tersebut digunakan untuk mengkalibrasi alat ukur aktivitas radionuclide calibrator .

Tujuan dari penelitian ini adalah meningkatkan kualitas hasil pengukuran dengan nilai ketidakpastian yang relatif lebih kecil. Dari hasil ini diharapkan pemanfaatan teknologi nuklir akan terlaksana secara aman bagi pasien, pekerja maupun masyarakat luas; tepat sasaran pada tujuan utama pengobatan; dan lebih akurat hasil pengukurannya.

\section{LANDASAN TEORI}

Prinsip dasar dari penggunaan metode ini adalah radionuklida yang akan diukur aktivitasnya mempunyai sifat peluruhan partikel beta dan foton/gamma secara serentak. Keserentakan antara beta dan gamma ini memungkinkan terjadinya koinsidensi. Dengan mengetahui nilai cacah partikel beta, foton/ gamma dan cacah koinsidensi maka dapat ditentukan secara ekstrapolasi aktivitas absolut dari suatu radionuklida. Karena radionuklida ${ }^{18} \mathrm{~F}$ mempunyai

skema peluruhan yang tidak kompleks (sederhana), maka persamaan koinsidensi adalah [4] :

$\mathrm{N}_{\beta}=\mathrm{N}_{\mathrm{o}} \mathrm{a}\left(\varepsilon_{\beta}+\left(1-\varepsilon_{\beta}\right) \varepsilon_{\beta \gamma}\right)$

$\mathrm{N}_{\gamma}=\mathrm{N}_{\mathrm{o}} 2$ a $\varepsilon_{\gamma}$

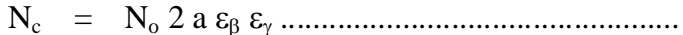

Dari persamaan (1), (2) dan (3), didapatkan :

$$
\frac{\mathrm{N}_{\beta} \mathrm{N}_{\gamma}}{\mathrm{N}_{\mathrm{c}}}=\mathrm{N}_{\mathrm{o}} \mathrm{a}\left[1+\frac{\left(1-\varepsilon_{\beta}\right)}{\varepsilon_{\beta}} \varepsilon_{\beta \gamma}\right]
$$

dengan : a adalah nilai branching ratio dari emisi $\beta$ $=$

$\beta$

0,9686 (19) [5]

$\mathrm{N}_{\mathrm{o}}$ adalah aktivitas sumber

$\mathrm{N}_{\beta}$ adalah nilai cacah pada saluran

$\mathbf{N}_{\gamma}$ adalah nilai cacah pada saluran $\gamma$

$\mathrm{N}_{\mathrm{c}}$ adalah nilai cacah pada saluran koinsidensi $\varepsilon_{\beta}$ adalah efisiensi beta $\varepsilon_{\gamma}$ adalah efisiensi gamma $\alpha$ adalah koefisien konversi $\varepsilon_{\beta \gamma}$ adalah efisiensi gamma dari detektor

beta

\section{METODE PENELITIAN}

A. Preparasi Sumber Radioaktif

Sumber radioisotop ${ }^{18} \mathrm{~F}$ didapatkan melalui reaksi ${ }^{18} \mathrm{O}(\mathrm{p}$, $\mathrm{n})^{18} \mathrm{~F}$ pada suatu pesawat pemercepat partikel bermuatan (cyclotron) yang dipasang di sebuah Rumah sakit di Jakarta. Pesawat ini mutlak diperlukan untuk menjamin ketersediaan sumber ${ }^{18} \mathrm{~F}$ secara berkelanjutan mengingat umur paro ${ }^{18} \mathrm{~F}$ yang hanya sekitar 110 menit. Sumber ${ }^{18} \mathrm{~F}$ yang dipreparasi dengan campuran larutan sintilasi cair ultima gold dimaksudkan untuk pengukuran yang menggunakan sistem koinsidensi $4 \pi \beta(\mathrm{LS})-\gamma(\mathrm{NaI}(\mathrm{Tl})$ yang merupakan perangkat pengukuran aktivitas secara absolut [6]. Larutan sintilasi ultima gold sebanyak $10 \mathrm{ml}$ ditempatkan pada vial berukuran $20 \mathrm{ml}$, kemudian larutan radioaktif ${ }^{18} \mathrm{~F}$ diteteskan kedalam larutan sintilasi tersebut dengan berat tertentu. Setelah vial wadah larutan tersebut ditutup selanjutnya dikocok agar larutan menjadi homogen dan ditempatkan pada lokasi yang tidak terkena cahaya. Larutan latar dibuat dari larutan sintilasi sebanyak $10 \mathrm{ml}$ dan tempatkan pada vial $20 \mathrm{ml}$ yang sama spesifikasinya dengan vial sebelumnya. Setelah sumber radioaktif diperkirakan telah homogen dengan larutan sintilasinya, maka sumber ${ }^{18} \mathrm{~F}$ siap untuk diukur (gambar 1). Jumlah sumber yang dibuat untuk jenis ini sebanyak 1 buah. Untuk cacah latar digunakan larutan ultima gold tanpa sumber radioaktif. 


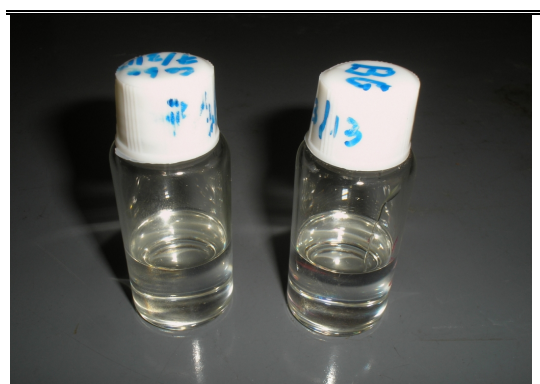

Gambar 1. Sumber ${ }^{18} \mathrm{~F}$ dalam wadah vial.

B. Pengukuran dengan perangkat absolut koinsidensi $4 \pi \beta(\mathrm{LS})-\gamma(\mathrm{NaI}(\mathrm{Tl})$.

Sistem koinsidensi $4 \pi \beta(\mathrm{LS})-\gamma(\mathrm{NaI}(\mathrm{Tl})$ dirangkai seperti pada gambar 2 di bawah ini [7]. Adapun setting yang dilakukan pada sistem perangkat tersebut adalah tegangan kerja untuk detektor beta anoda adalah 2600 volt, beta focus adalah 700 volt, detektor gamma adalah 750 volt, diskriminator beta adalah 30 mvolt (lower level), gerbang saluran gamma pada energi $511 \mathrm{keV}$, waktu mati beta dan gamma $50 \mu \mathrm{s}$, resolving time saluran beta adalah $1 \mu \mathrm{s}$, resolving time saluran koinsidensi adalah $2 \mu \mathrm{s}$, dan shaping time adalah $3 \mu \mathrm{s}$. Setting dilakukan agar efisiensi detektor menjadi semakin lebih tinggi sehingga nilai akurasi hasil pengukuran semakin tinggi pula.

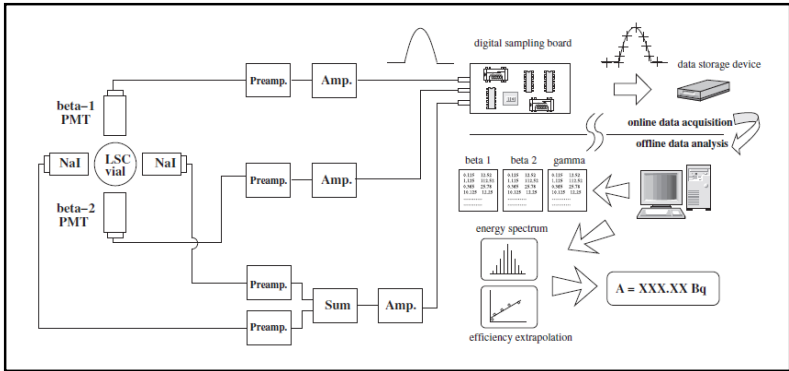

Gambar 2. Diagram perangkat koinsidensi $4 \pi \beta(\mathrm{LS})-$ $\gamma(\mathrm{NaI}(\mathrm{Tl})$ sistim digital.

Gambar 2 menunjukkan suatu diagram balok dari sistem koinsidensi yang diolah secara digital. Keluaran dari masing-masing detektor $\mathrm{NaI}$ diberi penguat awal, kemudian dijumlahkan dengan menggunakan modul suminvert. Setelah diperkuat dengan amplifier kemudian diteruskan ke sistem ADC (Analog to Digital Converter) yang pada Gambar 2 disebut digital sampling board untuk proses digitalisasi. Untuk sinyal beta yang keluar dari PMT 1 dan PMT 2 masing-masing diberi penguat awal (preamplifier), kemudian diberi penguat dengan amplifier, dan diteruskan ke sistem ADC.

Sumber radionuklida ${ }^{18} \mathrm{~F}$ yang terdapat dalam wadah vial berukuran $20 \mathrm{~mL}$ ditempatkan pada ruang pencacahan (counting chamber) yang terletak diantara dua buah tabung pengganda cahaya atau PMT (photo multiplier tube) dan dua buah detektor sinar gamma. Vial yang berisi sumber ${ }^{18} \mathrm{~F}$ dimasukkan ke dalam ruang pencacahan secara manual melalui lubang yang terletak diatas ruang tersebut. Untuk menghindari masuknya cahaya atau sinar dari luar yang dapat mengganggu pengukuran, lubang tersebut ditutup rapat dengan bahan/kain hitam.

\section{HASIL DAN PEMBAHASAN}

Hasil penimbangan sampel ${ }^{18} \mathrm{~F}$ bentuk titik maupun cairan dalam wadah ampul ditampilkan pada Tabel 1. Data penimbangan sampel berbentuk titik dibuat dengan berat yang hampir sama, hal ini dibuat untuk menghindari efek absorpsi diri (self absorption). Sedangkan untuk sumber cair dalam wadah ampul dibuat berbeda untuk keperluan kalibrasi alat ukur radionuclide calibrator.

Tabel 1. Data Penimbangan Sumber ${ }^{18} \mathrm{~F}$

\begin{tabular}{ccc}
\hline No & Bentuk & Berat $(\mathrm{mg})$ \\
\hline V1801/10 & Vial $(10 / 20) \mathrm{mL}$ & 14,23 \\
V1801/16 & Vial $(16 / 20) \mathrm{mL}$ & 16083,25 \\
V1802/16 & Vial $(16 / 20) \mathrm{mL}$ & 15876,68 \\
V1803/16 & Vial $(16 / 20) \mathrm{mL}$ & 15948,46 \\
\hline
\end{tabular}

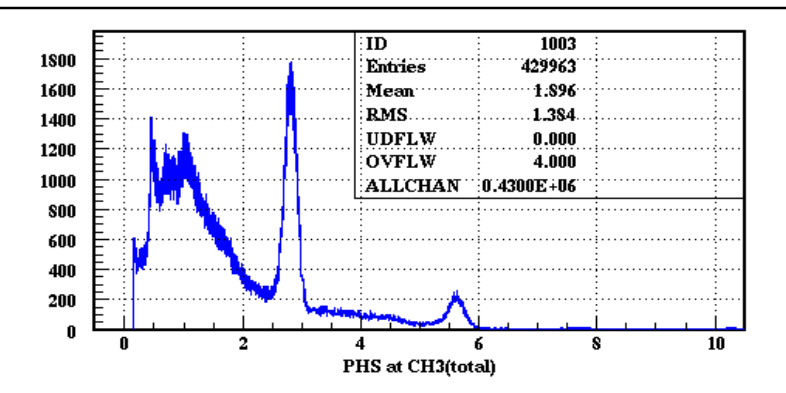

Gambar 3. Spektrum sinar gamma ${ }^{18} \mathrm{~F}$ menggunakan detektor $\mathrm{NaI}(\mathrm{Tl})$ pada sistim koinsidensi $4 \pi \beta(\mathrm{LS})-\gamma$
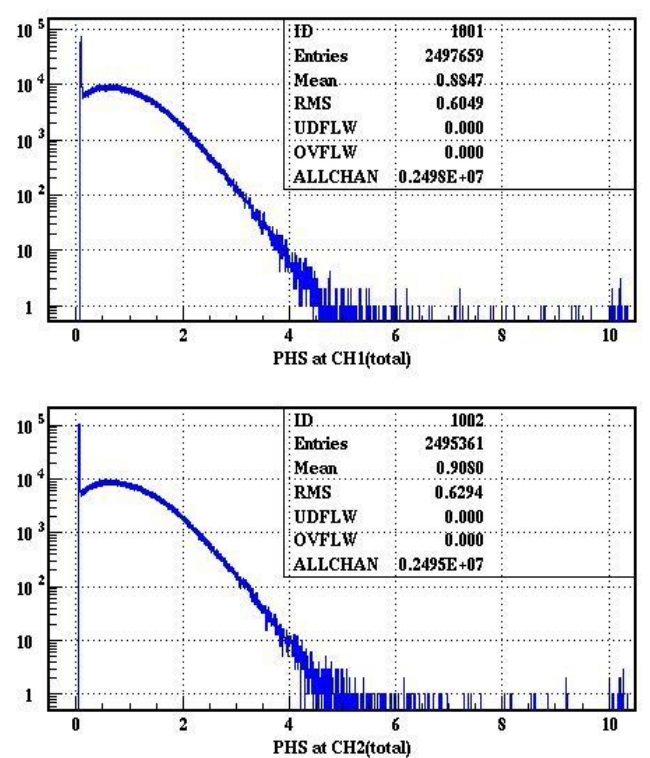
Gambar 4. Spektrum beta ${ }^{18} \mathrm{~F}$ menggunakan detektor

Liquid Scintilation pada sistim koinsidensi $4 \pi \beta(\mathrm{LS})-\gamma$.

Spektrum sinar gamma dari ${ }^{18} \mathrm{~F}$ yang didapat dengan menggunakan detektor $\mathrm{NaI}(\mathrm{Tl})$ pada sistim koinsidensi $4 \pi \beta(\mathrm{LS})-\gamma$, ditampilkan pada Gambar 3. Pada gambar tersebut sangat jelas terlihat spektrum gamma pada energi $511 \mathrm{keV}$. Pada sisi sebelah kanan terlihat spektrum gamma pada energi sekitar $1022 \mathrm{keV}$. Spektrum tersebut merupakan puncak jumlahan (sum-peak) antara energi $511 \mathrm{keV}$ dari peristiwa efek Compton dan dari peristiwa anihilasi. Bila dibandingkan dengan spektrum ${ }^{18} \mathrm{~F}$ menggunakan detektor semikonduktor HPGe maka detektor HPGe memiliki resolusi lebih baik, tetapi detektor sintilasi $\mathrm{NaI}(\mathrm{Tl})$ memiliki efisiensi yang lebih tinggi. Gambar 4 menampilkan spek-trum beta ${ }^{18} \mathrm{~F}$ yang didapat dari kedua PMT (photo multiflier tube) beta dengan detektor Liquid Scintilation pada sistim koinsidensi $4 \pi \beta(\mathrm{LS})-\gamma$. Kedua spektrum beta tersebut terlihat simetris yang menandakan bahwa setting saluran beta dari sistim koinsidensi sangat baik.

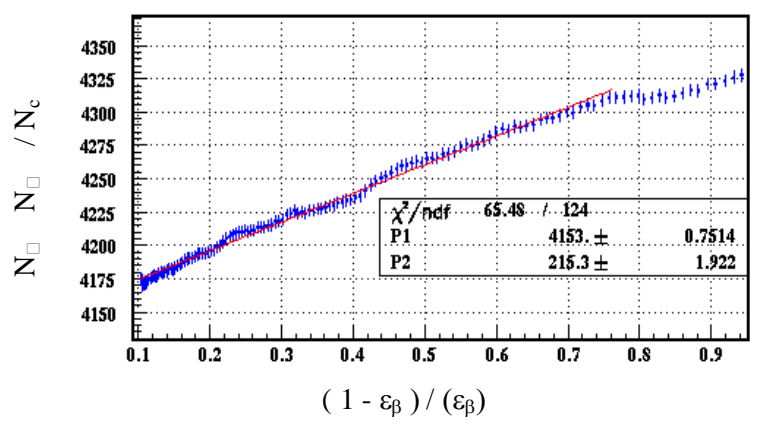

\section{Gambar 5. Kurva ekstrapolasi efisiensi ${ }^{18} \mathrm{~F}$}

Gambar 5 menampilkan kurva ekstrapolasi efisiensi ${ }^{18} \mathrm{~F}$ menggunakan sistim koinsidensi $4 \pi \beta(\mathrm{LS})-\gamma \mathrm{NaI}(\mathrm{Tl})$. Hasil pengukuran aktivitas secara absolut ditentukan melalui ekstrapolasi efisiensi pada $\left(1-\varepsilon_{\beta}\right) / \varepsilon_{\beta}=0$ atau $\varepsilon_{\beta}=1$. Pada kurva tersebut dapat ditentukan nilai aktivitas sumber ${ }^{18} \mathrm{~F}$ yang dicuplik ke dalam vial $20 \mathrm{~mL}$ adalah $(4153 \pm$ 0,7514) Bq, dengan kemiringan (slope) sebesar (215,3 \pm 1,922). Dari nilai ini maka didapatkan nilai aktivitas jenis sebesar : 291,85 Bq/mg.

Ketidakpastian bentangan (expanded uncertainty) [8] pada pengukuran aktivitas ${ }^{18} \mathrm{~F}$ secara absolut menggunakan sistim koinsidensi $4 \pi \beta(\mathrm{LS})-\gamma \mathrm{NaI}(\mathrm{Tl})$, pada tingkat kepercayaan 95\%, k=2 ditampilkan pada Tabel 2. Pada tabel tersebut nilai ketidakpastiannya di bawah $1 \%(0,51 \%)$, hal ini membuktikan metode pengukuran aktivitas secara absolut memiliki tingkat akurasi dan presisi yang sangat tinggi. Dengan demikian nilai aktivitas yang didapat dari pengukuran dengan metode tersebut adalah $(291,85 \pm$ $1,49) \mathrm{Bq} / \mathrm{mg}$.

Tabel 2. Komponen ketidakpastian pengukuran aktivitas ${ }^{18} \mathrm{~F}$ dengan metode koinsidensi $4 \pi \beta(\mathrm{LS})-\gamma \mathrm{NaI}(\mathrm{Tl})$

\begin{tabular}{lcc}
\multirow{2}{*}{ Komponen } & \multicolumn{2}{c}{ Ketidakpastian (\%) } \\
\cline { 2 - 3 } & Tipe A & Tipe B \\
\hline Statistik pencacahan & 0,15 & - \\
Dead time & - & 0,01 \\
Resolving time & - & 0,01 \\
Berat ${ }^{18} \mathrm{~F}$ & - & 0,05 \\
Umur paro ${ }^{18} \mathrm{~F}$ & - & 0,0164 \\
Probabilitas pancaran $\beta{ }^{+18} \mathrm{~F}$ & - & 0,1962 \\
Intersep kurva ekstrapolasi & 0,0181 & - \\
Timing & - & 0,002 \\
Jumlah kuadrat & 0,0228 & 0,0415 \\
Ketidakpastian gabungan & \multicolumn{2}{c}{0,2536} \\
$\begin{array}{l}\text { Ketidakpastian bentangan } \\
\text { tingkat kepercayaan, 95\% }\end{array}$ & $(\mathrm{k}=2)$, & \multicolumn{2}{c}{0,51} \\
\hline
\end{tabular}

Dengan dimilikinya alat ukur primer koinsidensi $4 \mathrm{phi}$ $\beta(\mathrm{LS})-\gamma(\mathrm{NaI}(\mathrm{Tl}))$ di PTKMR-BATAN maka dapat dilakukan pengukuran dan kalibrasi alat ukur sekunder radionuclide calibrator Capintec CRC-7BT. Hasil pengukuran dengan sistim koinsidensi 4phi $\beta(\mathrm{LC})-\gamma(\mathrm{NaI}(\mathrm{Tl}))$ dengan nilai ketidakpastian di bawah $1 \%(0,51 \%)$, dapat menunjukkan peningkatan kualitas hasil pengukuran dengan sistim tersebut, seperti ditunjukkan pada Tabel 3 di bawah ini. Pada Tabel 3 jelas terlihat perbedaan nilai ketidakpastian bentangan yang didapat jika menggunakan metode koinsidensi dan metode spektrometri gamma.

Tabel 3. Nilai ketidakpastian antara kedua metode pengukuran ${ }^{18} \mathrm{~F}$.

\begin{tabular}{lccc}
\hline \multirow{2}{*}{ Metode } & \multicolumn{3}{c}{ Ketidakpastian bentangan $(\%)$} \\
\cline { 2 - 4 } & Standar & $\begin{array}{c}\text { Standar } \\
\text { Sekunder }\end{array}$ & $\begin{array}{c}\text { Dose Cal. } \\
\text { Pelanggan }\end{array}$ \\
\hline Spektrometri gamma & 3,47 & 5,59 & 6,28 \\
Koinsidensi $4 \pi \beta-\gamma$ & 0,51 & 4,41 & 5,39 \\
Koinsidensi $4 \pi \beta-\gamma$ & 0,51 & - & 2,90 \\
\hline
\end{tabular}

\section{KESIMPULAN}

Laboratorium standardisasi radionuklida pada Pusat Teknologi Keselamatan dan Metrologi Radiasi - Badan Tenaga Nuklir Nasional telah dapat meningkatkan hasil pengukuran untuk mengkalibrasi alat ukur aktivitas "dose calibrator" dengan nilai ketidakpastian bentangan sebesar 2,9\% dengan faktor cakupan, $\mathrm{k}=2$ dan tingkat kepercayaan $95 \%$.

\section{PUSTAKA}

[1] Gatot Wurdiyanto, Pujadi Marsoem, Hermawan Candra, and Wijono Paidi; Radioactivity Measurement of ${ }^{18} \mathrm{~F}$ in $16 \mathrm{~mL}$ vials for Calibration of Radionuclide Calibrators, International Journal of Applied Radiation and Isotopes, ELSEVIER, ISSN 0969-8043, Vol. 70. Issue 9 hal. 2237 $2239,2012$.

[2] Bureau Internationale De Poids Et Mesures, Comparison Results of F-18, BIPM.RI(II)-K1, F-18, 2002.

[3] Table de Radionucleides, Laboratoire de Metrologie des Rayonnements Ionisants, Medical Selection, Commissariat a I energie Atomique, 1982.

[4] Roteta, M., Garcia-Torano. E., Barguero, L. R., Standardization of ${ }^{18} \mathrm{~F}$ by Coincidence and LSC Methods, International Journal Applied Radiation and Isotopes, 64, 1199 - 1202, 2006. 
[5] BE, M. M, et al, Monographie - 5 : Table of Radionuclides, Bureau Internationale de Poids et Mesures (BIPM) , Francis, 2008.

[6] Gatot Wurdiyanto, Teknik pembuatan dan pengukuran sumber standar radioaktif, Buletin BATAN, Tahun XI, No. 3, Juli 1990.

[7] K.B.Lee, Jong Man Lee, Tae Soon Park, Pil Jei Oh, Sang Han Lee, Min Kie Lee., Application of digital sampling techniques for $4 \pi \beta(L S)-\gamma$ coincidence counting., Nuclear Instruments and Methods in Physics research A 626-627, 72-76, 2011

[8] Gatot Wurdiyanto, Pujadi dan Hermawan Candra., Metode Penentuan Kemampuan Ukur Terbaik (KUT) pada Perangkat Spektrometer Gamma., Prosiding Pertemuan Ilmiah XXVI, Himpunan Fisika Indonesia Jateng \& Yogyakarta, Universitas Muhammadiyah, Purworejo, 14 April 2012. 